\title{
Effects of site and season on movement frequencies and displacement patterns of juvenile sea scallops Placopecten magellanicus under natural hydrodynamic conditions in Nova Scotia, Canada
}

\author{
A. E. Carsen ${ }^{1, *}$, B. G. Hatcher ${ }^{2}$, R. E. Scheibling ${ }^{1}$, A. W. Hennigar ${ }^{1}$, L. H. Taylor ${ }^{1}$ \\ ${ }^{1}$ Department of Biology, Dalhousie University, Halifax, Nova Scotia, Canada B3H 4J1 \\ ${ }^{2}$ Department of Oceanography, Dalhousie University, Halifax, Nova Scotia, Canada B3H 4J1
}

\begin{abstract}
In this study, we examine the effect of site and season (spring vs fall) on the movement frequency and net displacement of juvenile sea scallops Placopecten magellanicus, and the relationship between the net movement direction of scallops and the near-bed current direction at 2 sites in Lunenburg Bay, Nova Scotia, Canada. At each site, a total of 150 and 100 individually marked juvenile sea scallops were released on the sea bed at 2 points (Stns 1 and 2) placed $50 \mathrm{~m}$ apart for the spring (March) and fall (September) studies. The movement frequency and net displacement of the scallops were monitored within a $10 \mathrm{~m}$ radius from the release point approximately once a week during the spring study, and once a day during the fall study. Current meters placed $60 \mathrm{~cm}$ off the sea bed recorded near-bed current velocity. There was a significant interaction between site and season on the movement frequency of scallops. Scallop activity was low during the spring study at both sites when $-30 \%$ of scallops were found at their release point on the sea bed after $30 \mathrm{~d}$. Scallops were much more mobile during the fall study when $<5 \%$ of scallops were found at their release point after $2 \mathrm{~d}$. However, the net daily displacement was $<3 \mathrm{~m}$ for more than $60 \%$ of scallops recorded. In $\sim 50 \%$ of the surveys, the net movement direction of scallops was significantly related to the direction of the main current vectors over daily to monthly periods, whereas in the other cases the net movement direction was independent of the direction of the main current vectors. The results of this study indicate that local hydrodynamics is not a good predictor of the swimming dispersion of juvenile $P$. magellanicus in natural habitats.
\end{abstract}

KEY WORDS: Currents - Displacement patterns - Juveniles - Movement frequencies - Placopecten magellanicus $\cdot$ Sea scallops

\section{INTRODUCTION}

Scallops (Class Bivalvia, Family Pectinidae) are well known for their swimming ability (Brand 1991). They swim by rapid closure of the valves ('clapping') which propels them through the water. Their movement trajectories can be divided into active (swimming) and passive (sinking) phases. Small scallops ( $<30 \mathrm{~mm}$ shell

\footnotetext{
- Present address: Skybox 010-101282, 4405 NW 73 Ave., Miami, Florida 33166-6436, USA.

E-mail: andres.carsen@icslink.net
}

height, $\mathrm{SH}$ ) tend to swim vertically, or in an ascending spiral, and therefore rely on advection by water currents for horizontal displacement (Manuel \& Dadswell 1991, 1993, Minchin 1992, Carsen 1994). At larger sizes $(\sim 50 \mathrm{~mm} \mathrm{SH})$, scallops are capable of extended (>2 m) level flight (Joll 1989, Dadswell \& Weihs 1990). Although predators are considered the main stimulant of scallop swimming (Brand 1991), scallops may also swim in response to unsuitable environmental conditions, high density of conspecifics or changes in current speed (Brand 1991).

The sea scallop is among the most important species of scallops in the world market (Brand 1991); its distri- 
bution extends from the Gulf of St. Lawrence to Cape Hatteras, North Carolina, USA (Posgay 1957). It is usually found in environments with strong currents in depths ranging from about 15 to $110 \mathrm{~m}$, and occurs in shallower water in the northen part of its range, where it has been reported at depths of $2 \mathrm{~m}$ (Naidu et al. 1989). Juvenile Placopecten magellanicus reach 20 to $30 \mathrm{~mm} \mathrm{SH}$ in $\sim 24 \mathrm{mo}$ after settlement (Naidu et al. 1989). Adults reach their commercial size (90 mm SH) in $\sim 4$ yr. Previous studies of movement and dispersion of adult $P$. magellanicus on Georges Bank (Northwest Atlantic), and other species of scallops elsewhere, have demonstrated or postulated a relationship between the net movement direction of scallops and the main current vectors (Moore \& Marshall 1967, Posgay 1981, Melvin et al. 1985, Joll 1989, Thouzeau 1991). Thouzeau et al. (1991) found that the distribution of P. magellanicus with increasing age on eastern Georges Bank was consistent with that expected due to advection by currents. In contrast, Hatcher et al. (in press) found that the direction of dispersion of 10000 juvenile $P$. magellanicus in bottom seeding trials in Lunenburg Bay, Nova Scotia, Canada, differed from that predicted from both tidal and residual current direction. However, in both flume and field studies the movement of juvenile $P$. magellanicus (10 to $30 \mathrm{~mm}$ SH) was significantly related to the flow velocity over the 5 to $6 \mathrm{~s}$ duration of swimming events (Carsen 1994). The high cost of equipment and the labour-intensive nature of suspended culture of scallops have stimulated interest in bottom culture of $P$. magellanicus in eastern Canada (Wildish et al. 1988, Hatcher et al. in press, Kleinman et al. in press). Bottom culture involves seeding the sea bed with large numbers of juvenile scallops for subsequent harvest by conventional means. This entails a lower economic investment, but may result in major losses of scallops through predation and dispersal be- yond the seeded area (Hatcher et al. 1993, in press). The aim of our study, done in the context of a larger program to investigate the feasibility of bottom culture of sea scallops in eastern Canada (Hatcher et al. 1993, in press, Barbeau et al. 1994, Kleinman et al. in press), was to quantify in detail the relationship between near-bed water currents and net movement vectors of individually marked juvenile $P$. magellanicus, to predict the dispersion of seeded scallops. The studies were conducted at 2 different sites and during contrasting seasons (spring vs fall) in order to measure the effect of these factors on the movement frequencies and the distributions of net displacement of juvenile sea scallops over extended periods. We also sought to determine if the net movement direction of scallops was significantly related to those of the main current vectors.

\section{MATERIALS AND METHODS}

Study sites. Two study sites were selected in Lunenburg, Nova Scotia, with defined hydrodynamic regimes (Sturley \& Leal 1991, Sturley et al. 1993) and naturally occurring populations of sea scallops a 'Bay Site', at the mouth of Corkum Island Channel $\left(44^{\circ}\right.$ $20.7^{\prime} \mathrm{N}, 64^{\circ} 18.8^{\prime} \mathrm{W}$ ) and a 'Channel Site', located in Eastern Point Gut $\left(44^{\circ} 21.1^{\prime} \mathrm{N}, 64^{\circ} 12.8^{\prime} \mathrm{W}\right)$ at the mouth of the bay (Fig. 1) (these correspond to Sites 2 \& 3 respectively in Barbeau et al. 1994 and Kleinman et al. in press). The substratum at the Bay Site is a mixture of granite and slate cobbles and shell fragments, embedded in silt-sized sediments. The mean depth is $8.5 \mathrm{~m}$ and the tidal range is 0.7 to $2.1 \mathrm{~m}$. This site is dominated by tidal flow, and current speeds (at $60 \mathrm{~cm}$ off the sea bed) range from 0 at slack water to $0.58 \mathrm{~m} \mathrm{~s}^{-1}$ at peak flow. Bottom temperature variations
Fig. 1. Placopecten magellanicus. Map showing the 2 sites used to examine the movement frequencies and displacement patterns of juvenile scallops in Lunenburg Bay, Nova Scotia, Canada

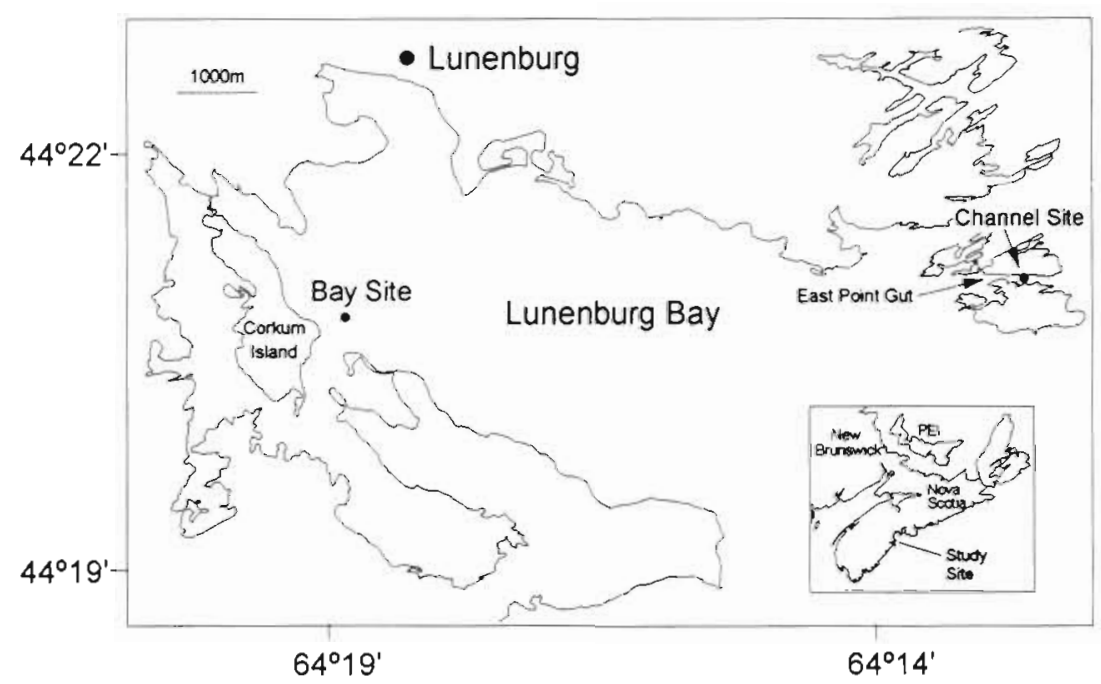


during the tidal cycle rarely exceed $6^{\circ} \mathrm{C}$ in spring and summer.

The Channel Site is more protected, lying within a $25 \mathrm{~m}$ wide tidal channel. The substratum at this site is similar to that at the Bay Site, but less uniform at scales of tens of metres. The mean depth in the Channel is $4.8 \mathrm{~m}$ and the tidal range is 0.7 to $1.9 \mathrm{~m}$. Current speeds range from 0.1 at slack water to $0.48 \mathrm{~m} \mathrm{~s}^{-1}$ at peak flow. The baroclinic currents in the channel are often strong enough to prevent tidal reversals in current direction, resulting in several days of unidirectional flows of varying speed. The temperature at the Channel Site is less variable than at the Bay Site, with tidal period variations rarely exceeding $3^{\circ} \mathrm{C}$.

Spring study. The scallops were obtained from an experimental hatchery at Sandy Cove, Nova Scotia (Fisheries Resource Development, Ltd) in late February 1992, and individually tagged with bee-tags (Steele \& Brodie, Ltd, Hampshire, England) glued to the dorsal valve. The bee-tags have a dish shape of $2.6 \mathrm{~mm}$ diameter, and $0.02 \mathrm{~mm}$ thickness, and weigh $0.0014 \mathrm{~g}$. The miniature bee-tags probably do not appreciably affect the behaviour or ability of juvenile scallops to swim. Parsons et al. (1992) found that plastic disk tags 3 times larger in diameter than the bee-tags used in our study did not affect the movement activity of juvenile Placopecten magellanicus. The shell height (the maximum distance between dorsal and ventral margin) of tagged scallops was recorded to the nearest $0.1 \mathrm{~mm}$ using vernier calipers. Prior to experiments, scallops were held in tanks with flowing seawater at ambient temperature and continually drip-fed with a mixture of cultured algae (T-Isochrysis galbana, Thalassiosira pseudonana and Chaetoceros muelleri).

At each site, 2 stations (Stns 1 and 2) were located $50 \mathrm{~m}$ apart along a line parallel to the major axis of current flow (Fig. 2). A reference marker $\sim 70 \mathrm{~cm}$ in height was placed $0.5 \mathrm{~m}$ from each station. On March 4 (Channel Site) and 18 (Bay Site), 1992, scallops were transported in coolers to the study sites, and 50 marked individuals of 15 to $29 \mathrm{~mm} \mathrm{SH}$ were released on the sea bed within a $-10 \mathrm{~cm}$ radius of each station marker. Additional scallops to replace those lost during the experiments were placed in pearl nets of $35 \times 35 \mathrm{~cm}, 6 \mathrm{~mm}$ mesh (50 per pearl net) and suspended $1 \mathrm{~m}$ above the sea bed at each station. From these pearl nets, a second set of 50 marked scallops was released at Stn 1 on April 4 at the Bay Site and on April 8 at the Channel Site.

Approximately $24 \mathrm{~h}$ after the scallops were released, the initial distance and bearing from the top of the reference marker to each scallop was recorded using a tape measure $( \pm 5 \mathrm{~cm}$ accuracy) and a magnetic compass ( $\pm 2^{\circ}$ accuracy) (Fig. 2 ). For each tagged scallop, the net movement distance and direction measured from the reference marker was adjusted to the actual release point (Stns 1 and 2) by trigonometry. The movement frequency, net movement distance and direction, and mortality (determined by recording intact and broken shells) of scallops was then monitored at approximately weekly intervals (March 19 to May 25, 1992, at the Bay Site; March 5 to May 19, 1992, at the Channel Site) by swimming circular transects within a $10 \mathrm{~m}$ radius of each station. To avoid scallop swimming reactions due to diving activity, we approached them very carefully. A scallop was considered to have moved when it was found at least $20 \mathrm{~cm}$ from its original position. Concurrent with this spring study, 20000 juvenile sea scallops were released on the sea bed between stations at the Bay Site and another 13000 at the Channel Site as part of a bottom seeding trial (Hatcher et al. 1993).

At both sites, 2 electromagnetic current meters (S4 Interocean Systems, San Diego, CA, USA) were used to record current velocity $\left[ \pm 1 \mathrm{~cm} \mathrm{~s}^{-1}\right.$ and $\pm 2^{\circ} \mathrm{M}$ (M is

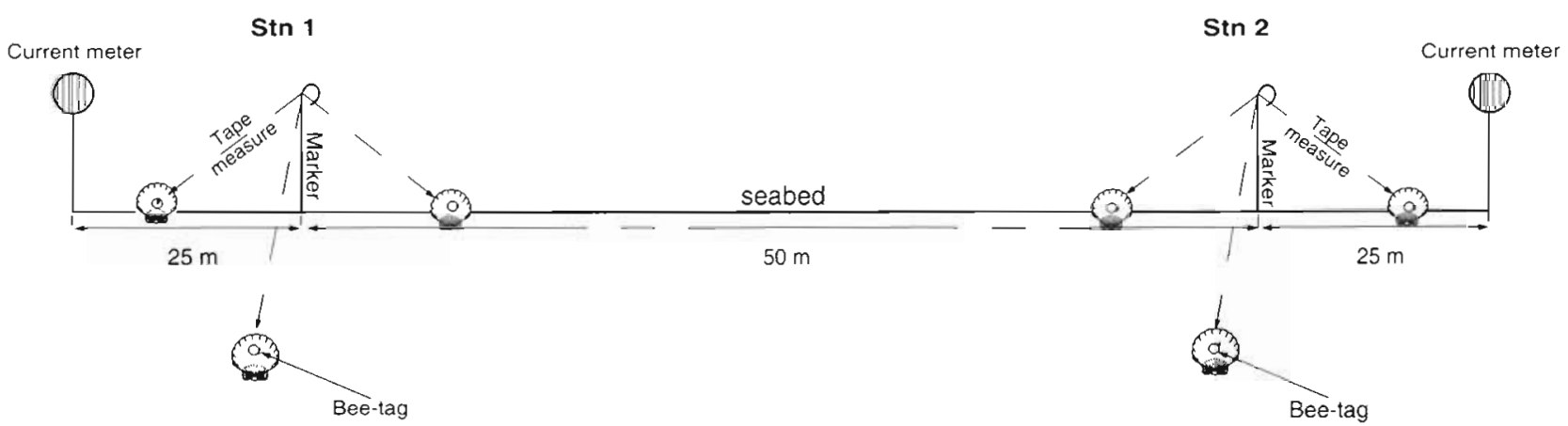

Fig. 2. Placopecten magellanicus. Schematic representation of the experimental set-up (not to scale). At each site, a total of 150 and 100 individually marked juvenile scallops were released on the sea bed at 2 points (Stns 1 and 2), placed $50 \mathrm{~m}$ apart for the spring and fall studies respectively. Current meters recording near-bed current velocity were placed at $60 \mathrm{~cm}$ off the sea bed either in the center of the transect ( 1 current meter) or at each end (2 current meters). The location of the marked scallops on the bed was monitored on a regular basis, within an area of $10 \mathrm{~m}$ radius from the release point 
direction with respect to magnetic north)] and temperature $\left( \pm 0.05^{\circ} \mathrm{C}\right)$ at $1.0 \mathrm{~min}$ intervals from March 18 to April 16 at the Bay Site and between March 4 and 31 at the Channel Site. Current meters were placed $100 \mathrm{~m}$ apart along the line parallel to the major axis of current flow at $0.6 \mathrm{~m}$ off the sea bed and $25 \mathrm{~m}$ upstream and downstream of each station, and their measurements were considered as those corresponding to Stns 1 and 2 respectively (Fig. 2). The S4 current meter spatially integrates the current velocity in a sphere of $\sim 50 \mathrm{~cm}$ radius with a spatial resolution of $2 \%$, which encompasses the height off the sea bed reached by juvenile scallops (Carsen 1994). Temperature was recorded using thermometers when there were no current meter data.

Fall study. The scallops were obtained from spat collectors in Passamaquoddy Bay, New Brunswick, Canada, through a commercial supplier (The Great Maritime Scallop Trading Co.). They were transported to the study sites on September 14 as described above for the spring trials, but placed in pearl nets at each station for $1 \mathrm{wk}$ prior to release on the sea bed. The experimental protocol used in the spring study was repeated in the fall using scallops in the same size range. However, the duration of the fall study was of $\sim 1$ wk (September 14 to 18 at the Bay Site; September 14 to 21 at the Channel Site) and the net movement distance and direction of the scallops were monitored at $\sim 24 \mathrm{~h}$ intervals due to the high movement frequency expected in this season (Hatcher et al. in press). On September 16, we estimated the number of scallop predators (starfish and crabs) in three $1 \mathrm{~m}$ wide circular transects around each station at 3,6 and $9 \mathrm{~m}$ from the marker using an underwater video camera. As only 2 current meters were available in the fall, we placed 1 at the midpoint between the 2 stations at each site.

Comparisons between the spring and fall studies could be confounded by the different sources of scallops: hatchery-reared in spring and wild in the fall. However, behavioural observations (Barbeau \& Scheibling 1994) and results of seeding trials (Hatcher et al. 1993) do not indicate an interaction between the scallop source and scallop behaviour or dispersion

Data analysis. For each tagged scallop, movement frequency and the net displacement and direction of movement were analysed in 2 ways. Firstly, each survey was considered separately, using the initial location of the scallop on the sea bed as a reference. Scallops were divided into 4 different groups: (1) 'dead', (2) 'moved' (scallops found within the search area but not at their initial release point), (3) 'not moved' (scallops found at their initial release point), and (4) 'not found'. The net displacement and direction of move- ment of scallops were examined using only the scallops which had moved. Secondly, the movement frequency of the scallops was analysed by monitoring the change in location of individual scallops on the sea bed between 2 consecutive surveys. Due to the high movement frequency during the fall, we estimated net displacement (using standard trigonometric functions) between 2 consecutive surveys at $1 \mathrm{~d}$ intervals.

For each site and survey, contingency table analysis was used to determine whether the observed proportion of scallops not found at their previous location on the sea bed ('moved' + 'not found') differed significantly between stations. In most cases the movement frequency within each site was independent of the station, so the interaction between site and season on the movement frequency of scallops ('moved' + 'not found') was analysed with a 2-way contingency table, pooling the data from both stations. The effect of season on the movement frequency of the scallops was examined by a separate contingency table analysis.

The observed distributions of net displacement of scallops for each survey were compared between stations at each season and site, and between sites after pooling stations, using a 2 sample KolmogorovSmirnov test. The Kolmogorov-Smirnov test also was used to compare distributions of net displacement between seasons at similar times after release. In the fall study, for the analysis of movement frequency and net displacement results, data from the first survey were not considered because of the short interval of time after release $(-3 \mathrm{~h})$.

Current meter data were analysed using the S4 software. Current velocity records (recorded every minute) were averaged over $10 \mathrm{~min}$ intervals to calculate mean current directions and speeds. Main current vectors were divided into 2 groups: (1) 'primary current vector' for the fastest, and (2) 'secondary current vector' for the next fastest current vector.

Circular statistics (Batschelet 1981) were used to test whether the observed distribution of net movement direction of scallops was significantly different from a random distribution (Rayleigh's test) and independent of the direction of the main current vectors ( $V$ test) for each survey. It may be argued that Hotelling's test, a bivariate analysis that includes both the vector distance and direction to test for directional movement (Batschelet 1981), could have been used instead of the Rayleigh or $V$ tests, which do not include the vector distance in the analysis. However, for a given survey, the vector distances did not vary much and their distribution could not be interpreted as drawn from a bivariate normal population, precluding the use of Hotelling's test (Batschelet 1981). This 
is supported by the fact that whenever the Rayleigh or $V$ tests showed significant directional movement, Hotelling's test failed to do so. In cases where the Rayleigh or the $V$ tests showed that the observed distribution of the vector angles was significantly different from a random distribution for both stations in the same survey, the mean vector angles between both stations were compared with the Watson and Williams test (Batschelet 1981).

\section{RESULTS}

\section{Environmental conditions}

Near-bed water temperature during the spring study increased from 1.5 to $8.5^{\circ} \mathrm{C}$ at the Bay Site and from 2 to $6.5^{\circ} \mathrm{C}$ at the Channel Site. During the first 4 wk of the spring study, water temperature was minimal at both sites, ranging from -1 to $2^{\circ} \mathrm{C}$. For the next $4 \mathrm{wk}$, water temperature at the Bay Site tended to be higher than at the Channel Site, and was $2^{\circ} \mathrm{C}$ higher at the end of the experiment. None of the differences in time-averaged monthly means was statistically significant (Student's $t$ test: $p>0.15)$. Water temperature during the fall study decreased from 12.5 to $9.6^{\circ} \mathrm{C}$ at the Bay Site, but remained relatively constant at 12.0 to $13.8^{\circ} \mathrm{C}$ at the Channel Site. Mean water $( \pm \mathrm{SE})$ temperature at the Bay Site $\left(9.88 \pm 0.12^{\circ} \mathrm{C}\right)$ was significantly lower (Student's t-test: $\mathrm{p}<0.001$ ) than at the Channel Site $\left(12.5 \pm 0.13^{\circ} \mathrm{C}\right)$.

The near-bed hydrodynamics at both sites was characterised by strong, bidirectional currents during both seasons. At the Bay Site, tidal forcing dominated the flows, with a strong asymmetry favouring the ebb. The direction of the main current vectors was more variable at the Bay Site than at the Channel Site (Fig. 3, Tables 1 to 4). At the Channel Site, low-frequency forcing often dominated over the tides, resulting in unidirectional flows over periods of several days. The direction of the main current vectors was fairly constant in the along-channel axis, during both study periods (Fig. 3, Tables 1 to 4 ).

During the fall study at both sites there were no significant differences (Student's $t$-test: $\mathrm{p}>0.10$ ) between stations in the mean density of predatory starfish Asterias spp. or crabs Cancer irroratus. Mean density $( \pm \mathrm{SE})$ pooled over stations was $0.80 \pm 0.09$ and $0.04 \pm$
0.03 ind. $\mathrm{m}^{-2}$ for starfish and crabs at the Bay Site and $0.70 \pm 0.16$ and $0.13 \pm 0.04$ ind. $\mathrm{m}^{-2}$ for starfish and crabs at the Channel Site respectively. There were no significant differences $(p>0.57)$ between sites in the mean density of starfish, but the density of crabs was higher $(p=0.05)$ at the Channel Site than at the Bay Site.

\section{Movement irequency}

Scallops at each station at each site usually exhibited similar movement frequencies as measured by the proportion of scallops that were not found at their release point. In the spring study, contingency table analysis showed that there were no significant differences in the movement frequency between stations in 5 out of 7 surveys at the Bay Site $\left(\chi^{2}<0.60, p>0.25\right)$ and in 6 out of 11 surveys at the Channel Site $(p>$ 0.20). A second set of scallops was released at Stn 1 on April 4 at the Bay Site and on April 8 at the Channel Site, but these were not included in the analysis. In the fall study, there were no significant differences in the movement frequency between stations for any survey $(p>0.25)$. Due to the low proportion of significant differences between stations, data for both sta-

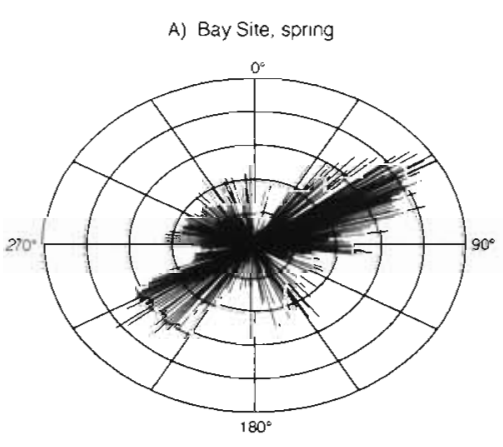

C) Bay Site, fall

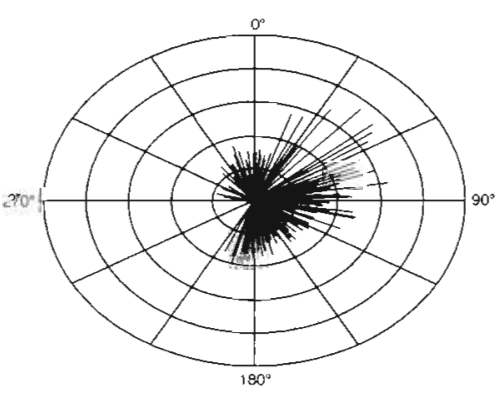

Fig. 3. Placopecten magellanicus. Time-integrated current vectors $\left(10 \mathrm{~cm} \mathrm{~s}^{-1}\right)$ at 2 study sites and seasons. For the spring study, current vectors correspond to those measured 7 and $5 \mathrm{~d}$ after scallops were released, at (A) the Bay Site and (B) the Channel Site respectively. For the fall study, current vectors correspond to those measured $4 \mathrm{~d}$ after scallops were released at (C) the Bay Site and (D) the Channel Site respectively. For the spring study, current vectors correspond to those measured at Stns 2 and 1 for the Bay and the Channel sites respectively. During the fall only 1 current meter was used. Current direction was recorded with respect to magnetic north 
Table 1. Placopecten magellanicus. Bay Site, spring study: mean net displacement and mean vector distance and angle of juvenile scallops released on the sea bed at 2 stations $50 \mathrm{~m}$ apart, and main current vectors as time-integrated direction and speed of primary and secondary main current vectors. $V$ test results appear in the same columns as the directions of primary and secondary main current vectors. ${ }^{\prime}$ and ' : directionality at the $95 \%$ and $99 \%$ level of confidence, respectively, for both Rayleigh and $V$ tests. Stn: station; Dir.: direction; Dist. distance; r: mean vector length; ns: not significant; nd: no data. 50 additional scallops were released on 22 April 1992 at Stn 1 (numbers within parentheses correspond to the second set of scallops)

\begin{tabular}{|c|c|c|c|c|c|c|c|c|c|c|c|}
\hline \multirow{3}{*}{$\begin{array}{l}\text { Survey } \\
\text { date }\end{array}$} & \multirow{3}{*}{$\begin{array}{l}\text { Elapsed } \\
\text { time (d) }\end{array}$} & \multirow[t]{3}{*}{ Stn } & \multirow{3}{*}{$\begin{array}{l}\text { Number } \\
\text { 'moved' }\end{array}$} & \multirow{3}{*}{$\begin{array}{c}\text { Mean net } \\
\text { displacement } \\
(\mathrm{cm} \pm \mathrm{SE})\end{array}$} & \multicolumn{3}{|c|}{ Mean scallop vector } & \multicolumn{4}{|c|}{ Main current vectors } \\
\hline & & & & & \multirow{2}{*}{$\begin{array}{c}\text { Dir. }\left({ }^{\circ} \mathrm{M}\right) \\
( \pm 95 \% \mathrm{CI})\end{array}$} & \multirow{2}{*}{$\begin{array}{l}\text { Dist. } \\
\text { (cm) }\end{array}$} & \multirow[t]{2}{*}{$r$} & \multicolumn{2}{|c|}{ Primary } & \multicolumn{2}{|c|}{ Secondary } \\
\hline & & & & & & & & $\begin{array}{l}\text { Dir. } \\
\left({ }^{\circ} \mathrm{M}\right)\end{array}$ & $\begin{array}{l}\text { Speed } \\
\left(\mathrm{cm} \mathrm{s}^{-1}\right)\end{array}$ & $\begin{array}{l}\text { Dir. } \\
\left({ }^{\circ} \mathrm{M}\right)\end{array}$ & $\begin{array}{c}\text { Speed } \\
\left(\mathrm{cm} \mathrm{s}^{-1}\right)\end{array}$ \\
\hline $19 \mathrm{Mar}$ & 1 & 1 & 4 & $112 \pm 25$ & 354 & 20 & $0.14^{\mathrm{r}] \mathrm{s}}$ & $60^{\text {ns }}$ & 10 & $250^{\text {ns }}$ & 25 \\
\hline $19 \mathrm{Mar}$ & 1 & 2 & 5 & $56 \pm 7$ & 288 & 26 & $0.45^{\mathrm{ns}}$ & $65^{\text {ns }}$ & 15 & $235^{\mathrm{ns}}$ & 5 \\
\hline $20 \mathrm{Mar}$ & 2 & 1 & 4 & $95 \pm 17$ & 316 & 10 & $0.15^{\mathrm{ns}}$ & $55^{\text {ns }}$ & 15 & $250^{\text {ns }}$ & 20 \\
\hline $20 \mathrm{Mar}$ & 2 & 2 & 4 & $42 \pm 5$ & 276 & 22 & $0.48^{\text {ns }}$ & $65^{\text {ns }}$ & 20 & $235^{\mathrm{ns}}$ & 5 \\
\hline $25 \mathrm{Mar}$ & 7 & 1 & 4 & $93 \pm 24$ & 82 & 21 & $0.44^{\mathrm{ns}}$ & $55^{\text {ns }}$ & 25 & $110^{\text {ns }}$ & 18 \\
\hline $25 \mathrm{Mar}$ & 7 & 2 & 20 & $46 \pm 4$ & $0 \pm 34$ & 23 & $0.54^{*}$ & $60^{\cdots}$ & 18 & 235 & 5 \\
\hline $16 \mathrm{Apr}$ & 29 & 1 & 3 & $138 \pm 52$ & 261 & 111 & $0.55^{\mathrm{ns}}$ & $55^{\mathrm{ns}}$ & 10 & $105^{\mathrm{ns}}$ & 15 \\
\hline $16 \mathrm{Apr}$ & 29 & 2 & 15 & $87 \pm 20$ & $18 \pm 46$ & 55 & $0.45^{\circ}$ & $55^{*}$ & 15 & $235^{\mathrm{ns}}$ & 5 \\
\hline $22 \mathrm{Apr}$ & 35 & 1 & 5 & $98 \pm 30$ & 54 & 60 & $0.44^{\mathrm{ns}}$ & nd & nd & nd & nd \\
\hline $22 \mathrm{Apr}$ & 35 & 2 & 20 & $109 \pm 21$ & $31 \pm 46$ & 70 & $0.48^{\prime}$ & nd & nd & nd & nd \\
\hline $27 \mathrm{Apr}$ & 40 & 1 & 7 & $115 \pm 30$ & 13 & 51 & $0.27^{\mathrm{ns}}$ & nd & nd & nd & nd \\
\hline $27 \mathrm{Apr}$ & (5) & 1 & (12) & $(190 \pm 29)$ & $(33 \pm 45)$ & $(141)$ & $\left(0.67^{\circ}\right)$ & nd & nd & nd & nd \\
\hline $27 \mathrm{Apr}$ & 40 & 2 & nd & nd & nd & nd & nd & nd & nd & nd & nd \\
\hline 4 May & 47 & 1 & 8 & $190 \pm 70$ & $87 \pm 50$ & 160 & $0.65^{\circ}$ & nd & nd & nd & nd \\
\hline 4 May & $(12)$ & 1 & (9) & $(151 \pm 28)$ & $(114 \pm 55)$ & $(97)$ & $\left(0.58^{\circ}\right)$ & nd & nd & nd & nd \\
\hline 4 May & 47 & 2 & 11 & $146 \pm 45$ & 325 & 75 & $0.48^{\mathrm{ns}}$ & nd & nd & nd & nd \\
\hline 25 May & 68 & 1 & 6 & $163 \pm 54$ & 25 & 31 & 0.35 & nd & nd & nd & nd \\
\hline $25 \mathrm{May}$ & (33) & 1 & (10) & $(520 \pm 113)$ & $(35 \pm 45)$ & $(447)$ & $\left(0.63^{\circ}\right)$ & nd & nd & nd & nd \\
\hline 25 May & 68 & 2 & 5 & $243 \pm 93$ & 351 & 129 & $0.01^{\text {ns }}$ & nd & nd & nd & nd \\
\hline
\end{tabular}

tions were pooled in testing for site and season effects (Figs. 4 \& 5). For surveys up to $7 \mathrm{~d}$ after release (for which comparisons between seasons could be made), contingency table analysis showed that the effect of site was not independent of season $(\mathrm{p}<0.05)$ (Fig. 4).
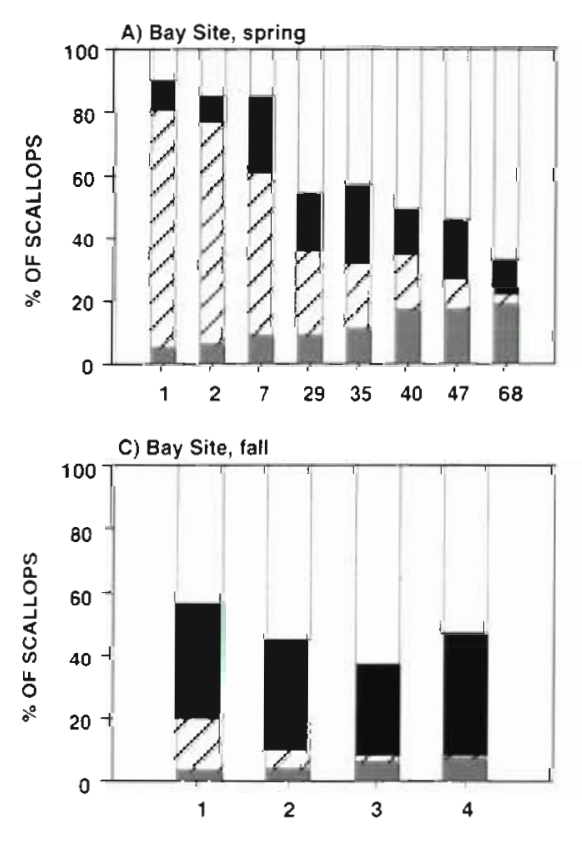

TIME ELAPSED AFTER RELEASE (d)
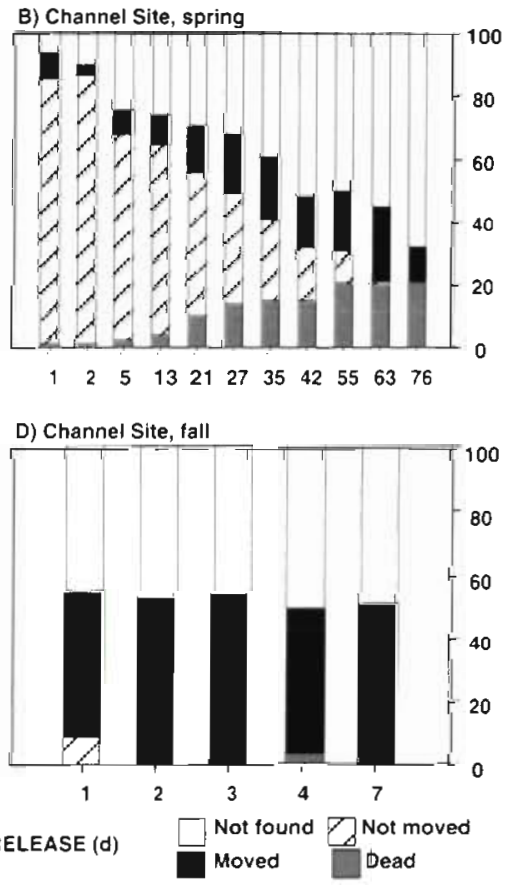

Fig. 4. Placopecten magellanicus. Percentage frequency histograms showing, for each survey independently, the effect of (A-B, C-D) site and $(A-C, B-D)$ season on the proportion of juvenile scallops found at their release point on the sea bed ('not moved'), not found at their release point but found within the search area ('moved'), not found at their release point or within the search area (not found') and mortality within the search area ('dead'). For each site and season, data from both stations were pooled. The second set of scallops released at Stn 1 in the spring at both study sites is not included 
Table 2. Placopecten magellanicus. Channel Site, spring study: mean net displacement and mean vector distance and angle of juvenile scallops released on the sea bed at 2 stations $50 \mathrm{~m}$ apart, and main current vectors as time-integrated direction and speed of primary and secondary main current vectors. ' and $\cdots$ directionality at the $95 \%$ and $99 \%$ level of confidence, respectively, for both Rayleigh and $V$ tests. $V$ test results appear in the same columns as the directions of primary and secondary current vectors. Stn: station; Dir.: direction; Dist:: distance; $r$ : mean vector length; ns: not significant; nd: no data. 50 additional scallops were released on 8 April 1992 at Stn 1 (numbers within parentheses correspond to the second set of scallops)

\begin{tabular}{|c|c|c|c|c|c|c|c|c|c|c|c|}
\hline \multirow{3}{*}{$\begin{array}{l}\text { Survey } \\
\text { date }\end{array}$} & \multirow{3}{*}{$\begin{array}{l}\text { Elapsed } \\
\text { time (d) }\end{array}$} & \multirow{3}{*}{ Stn } & \multirow{3}{*}{$\begin{array}{l}\text { Number } \\
\text { 'moved' }\end{array}$} & \multirow{3}{*}{$\begin{array}{c}\text { Mean net } \\
\text { displacement } \\
(\mathrm{cm} \pm \mathrm{SE})\end{array}$} & \multicolumn{3}{|c|}{ Mean scallop vector } & \multicolumn{4}{|c|}{ Main current vectors } \\
\hline & & & & & Dir. $\left({ }^{\circ} \mathrm{M}\right)$ & Dist. & r & & imary & Sec & ondary \\
\hline & & & & & $( \pm 95 \% \mathrm{Cl})$ & $(\mathrm{cm})$ & & $\begin{array}{l}\text { Dir. } \\
\left({ }^{\circ} \mathrm{M}\right)\end{array}$ & $\begin{array}{c}\text { Speed } \\
\left(\mathrm{cm} \mathrm{s}^{-1}\right)\end{array}$ & $\begin{array}{l}\text { Dir. } \\
\left({ }^{\circ} \mathrm{M}\right)\end{array}$ & $\begin{array}{c}\text { Speed } \\
\left(\mathrm{cm} \mathrm{s}^{-1}\right)\end{array}$ \\
\hline $5 \mathrm{Mar}$ & 1 & 1 & 4 & $58 \pm 8$ & $277 \pm 45$ & 44 & $0.80^{\circ}$ & $280^{\mathrm{ns}}$ & 12 & $240^{\text {ns }}$ & 6 \\
\hline 5 Mar & 1 & 2 & 4 & $44 \pm 6$ & $120 \pm 43$ & 41 & $0.91^{\circ}$ & $280^{\mathrm{ns}}$ & 12 & $240^{\text {ns }}$ & 6 \\
\hline $6 \mathrm{Mar}$ & 2 & 1 & 3 & $55 \pm 15$ & 85 & 10 & $0.11^{\mathrm{ns}}$ & $305^{\text {ns }}$ & 28 & $245^{\text {ns }}$ & 6 \\
\hline $6 \mathrm{Mar}$ & 2 & 2 & nd & nd & nd & nd & nd & 305 & 23 & 245 & 6 \\
\hline 9 Mar & 5 & 1 & 7 & $60 \pm 5$ & 340 & 16 & $0.40^{\text {ns }}$ & $110^{\mathrm{ns}}$ & 23 & $280^{\mathrm{ns}}$ & 6 \\
\hline 9 Mar & 5 & 2 & 1 & 35 & 122 & 35 & nd & 305 & 23 & 245 & 6 \\
\hline $17 \mathrm{Mar}$ & 13 & 1 & 5 & $45 \pm 6$ & 354 & 36 & $0.62^{\text {ns }}$ & $120^{\text {ns }}$ & 25 & $75^{\mathrm{ns}}$ & 6 \\
\hline $17 \mathrm{Mar}$ & 13 & 2 & 4 & $82 \pm 24$ & $122 \pm 16$ & 81 & $0.99 \cdot$ & $110^{\circ}$ & 27 & $280^{\mathrm{ns}}$ & 6 \\
\hline $25 \mathrm{Mar}$ & 21 & 1 & 9 & $50 \pm 7$ & 330 & 15 & $0.40^{\mathrm{ns}}$ & $120^{\mathrm{ns}}$ & 25 & $250^{\text {ns }}$ & 6 \\
\hline $25 \mathrm{Mar}$ & 21 & 2 & 6 & $64 \pm 18$ & $123 \pm 16$ & 62 & $0.97^{\cdots}$ & $115^{\circ}$ & 23 & $350^{\text {ns }}$ & 6 \\
\hline $31 \mathrm{Mar}$ & 27 & 1 & 11 & $74 \pm 11$ & $322 \pm 68$ & 21 & $0.53^{\circ}$ & $115^{\mathrm{ns}}$ & 35 & $230^{\mathrm{ns}}$ & 6 \\
\hline $31 \mathrm{Mar}$ & 27 & 2 & 8 & $50 \pm 6$ & $108 \pm 41$ & 36 & $0.69^{\circ}$ & $115^{\circ}$ & 30 & $335^{\mathrm{ns}}$ & 6 \\
\hline $8 \mathrm{Apr}$ & 35 & 1 & 8 & $70 \pm 7$ & 275 & 29 & $0.23^{\text {ns }}$ & nd & nd & nd & nd \\
\hline $8 \mathrm{Apr}$ & 35 & 2 & 12 & $89 \pm 19$ & $155 \pm 40$ & 67.2 & $0.61^{\circ}$ & nd & nd & nd & nd \\
\hline $15 \mathrm{Apr}$ & 42 & 1 & 5 & $45 \pm 11$ & 40 & 8 & $0.42^{\mathrm{ns}}$ & nd & nd & nd & nd \\
\hline $15 \mathrm{Apr}$ & (7) & 1 & (9) & $(83 \pm 4)$ & $(116 \pm 35)$ & (59) & $\left(0.78^{\circ}\right)$ & nd & nd & nd & nd \\
\hline $15 \mathrm{Apr}$ & 42 & 2 & 11 & $56 \pm 13$ & $176 \pm 38$ & 40 & $0.57^{\circ}$ & nd & nd & nd & nd \\
\hline $28 \mathrm{Apr}$ & 55 & 1 & 6 & $106 \pm 22$ & 94 & 18 & $0.21^{\mathrm{ns}}$ & nd & nd & nd & nd \\
\hline $28 \mathrm{Apr}$ & $(20)$ & 1 & (7) & $(115 \pm 33)$ & $(171 \pm 55)$ & $(62)$ & $\left(0.64^{n s}\right)$ & nd & nd & nd & nd \\
\hline $28 \mathrm{Apr}$ & 55 & 2 & 13 & $100 \pm 38$ & $197 \pm 52$ & 50 & $0.52^{\circ}$ & nd & nd & nd & nd \\
\hline 6 May & 63 & 1 & 6 & $116 \pm 35$ & 350 & 91 & $0.58^{\mathrm{ns}}$ & nd & nd & nd & nd \\
\hline 6 May & $(28)$ & 1 & $(8)$ & $(329 \pm 118)$ & $(155 \pm 33)$ & (318) & $\left(0.80^{\circ}\right)$ & nd & nd & nd & nd \\
\hline 6 May & 63 & 2 & 18 & $160 \pm 44$ & $223 \pm 43$ & 74 & $0.47^{\circ}$ & nd & nd & nd & nd \\
\hline 19 May & 76 & 1 & nd & nd & nd & nd & nd & nd & nd & nd & nd \\
\hline 19 May & (41) & 1 & $(2)$ & $(248 \pm 10)$ & (193) & (233) & $\left(0.80^{\mathrm{ns}}\right)$ & nd & nd & nd & nd \\
\hline 19 May & 76 & 2 & 11 & $146 \pm 47$ & 198 & 65 & $0.47^{\mathrm{ns}}$ & nd & nd & nd & nd \\
\hline
\end{tabular}

Table 3. Placopecten magellanicus. Bay Site, fall study: mean net displacement and mean vector distance and angle of juvenile scallops released on the sea bed at 2 stations $50 \mathrm{~m}$ apart, and main current vectors as time-integrated direction and speed of primary and secondary main current vectors. " and " $"$ : directionality at the $95 \%$ and $99 \%$ level of confidence, respectively, for both Rayleigh and $V$ tests. $V$ test results appear in the same columns as the directions of primary and secondary current vectors. Stn: station; Dir.: direction; Dist.: distance; $r$ : mean vector length; ns: not significant. ${ }^{a}$ Cases in which the $V$ test showed a significant directional movement of scallops, but Rayleigh's test failed to do so

\begin{tabular}{|c|c|c|c|c|c|c|c|c|c|c|c|}
\hline \multirow{3}{*}{$\begin{array}{l}\text { Survey } \\
\text { date }\end{array}$} & \multirow{3}{*}{$\begin{array}{l}\text { Elapsed } \\
\text { time (d) }\end{array}$} & \multirow{3}{*}{ Stn. } & \multirow{3}{*}{$\begin{array}{l}\text { Number } \\
\text { 'moved }\end{array}$} & \multirow{3}{*}{$\begin{array}{c}\text { Mean net } \\
\text { displacement } \\
(\mathrm{cm} \pm \mathrm{SE})\end{array}$} & \multicolumn{3}{|c|}{ Mean scallop vector } & \multicolumn{4}{|c|}{ Main current vectors } \\
\hline & & & & & \multirow{2}{*}{$\begin{array}{c}\text { Dir. }\left({ }^{\circ} \mathrm{M}\right) \\
( \pm 95 \% \mathrm{Cl})\end{array}$} & \multirow{2}{*}{$\begin{array}{l}\text { Dist. } \\
\text { (cm) }\end{array}$} & \multirow[t]{2}{*}{ r } & \multicolumn{2}{|c|}{ Primary } & \multicolumn{2}{|c|}{ Secondary } \\
\hline & & & & & & & & $\begin{array}{l}\text { Dir. } \\
\left({ }^{\circ} \mathrm{M}\right)\end{array}$ & $\begin{array}{c}\text { Speed } \\
\left(\mathrm{cm} \mathrm{s}^{-1}\right)\end{array}$ & $\begin{array}{l}\text { Dir. } \\
\left({ }^{\circ} \mathrm{M}\right)\end{array}$ & $\begin{array}{c}\text { Speed } \\
\left(\mathrm{cm} \mathrm{s}^{-1}\right)\end{array}$ \\
\hline $14 \mathrm{Sep}$ & 0.1 & 1 & 18 & $323 \pm 47$ & $88 \pm 28$ & 231 & $0.66^{\circ}$ & $90^{\circ}$ & 23 & $50^{\mathrm{ns}}$ & 5 \\
\hline 14. Sep & 0.1 & 2 & 13 & $205 \pm 33$ & $72 \pm 90^{\mathrm{a}}$ & 94 & $0.37^{\mathrm{ns}}$ & $90^{\circ}$ & 23 & $50^{\circ}$ & 5 \\
\hline $15 \mathrm{Sep}$ & 1 & 1 & 20 & $373 \pm 52$ & $73 \pm 26$ & 296 & $0.64^{\cdot \cdot}$ & $80^{*}$ & 23 & $350^{\mathrm{ns}}$ & 5 \\
\hline $15 \mathrm{Sep}$ & 1 & 2 & 17 & $222 \pm 39$ & $75 \pm 55^{a}$ & 78 & $0.35^{\text {ns }}$ & $80^{\circ}$ & 23 & $350^{\mathrm{ns}}$ & 5 \\
\hline $16 \mathrm{Sep}$ & 2 & 1 & 18 & $341 \pm 55$ & $73 \pm 50^{\mathrm{a}}$ & 208 & $0.40^{\mathrm{ns}}$ & $100^{\circ}$ & 23 & $205^{n s}$ & 5 \\
\hline $16 \mathrm{Sep}$ & 2 & 2 & 17 & $266 \pm 72$ & $109 \pm 45$ & 186 & $0.47^{\circ}$ & $100^{\cdots}$ & 23 & $205^{\text {ns }}$ & 5 \\
\hline $17 \mathrm{Sep}$ & 3 & 1 & 13 & $313 \pm 46$ & $68 \pm 52$ & 113 & $0.51^{\bullet}$ & $105^{\circ}$ & 20 & $205^{\mathrm{ns}}$ & 5 \\
\hline 17 Sep & 3 & 2 & 16 & $316 \pm 78$ & $197 \pm 54^{\mathrm{a}}$ & 119 & $0.41^{\mathrm{ns}}$ & $105^{\mathrm{ns}}$ & 20 & $205^{\circ}$ & 5 \\
\hline $18 \mathrm{Sep}$ & 4 & 1 & 25 & $399 \pm 49$ & $120 \pm 110^{\mathrm{a}}$ & 136 & $0.25^{\mathrm{ns}}$ & $100^{\circ}$ & 15 & $130^{\circ}$ & 5 \\
\hline $18 \mathrm{Sep}$ & 4 & 2 & 14 & $271 \pm 51$ & 186 & 118 & $0.25^{\text {ns }}$ & $100^{\mathrm{ns}}$ & 15 & $130^{\mathrm{ns}}$ & 5 \\
\hline
\end{tabular}


Table 4. Placopecten magellanicus. Channel Site, fall study: mean net displacement and mean vector distance and angle of juvenile scallops released on the sea bed at 2 stations $50 \mathrm{~m}$ apart, and main current vectors as time-integrated direction and speed of primary and secondary main current vectors. "and " : directionality at the $95 \%$ and $99 \%$ level of confidence, respectively, for both Rayleigh and $V$ tests. $V$ test results appear in the same columns as the directions of primary and secondary current vectors.

Stn: station; Dir.: direction; Dist.: distance; r: mean vector length; ns: not significant; nd: no data

\begin{tabular}{|c|c|c|c|c|c|c|c|c|c|c|c|}
\hline \multirow{3}{*}{$\begin{array}{l}\text { Survey } \\
\text { date }\end{array}$} & \multirow{3}{*}{$\begin{array}{l}\text { Elapsed } \\
\text { time (d) }\end{array}$} & \multirow[t]{3}{*}{ Stn } & \multirow{3}{*}{$\begin{array}{l}\text { Number } \\
\text { 'moved' }\end{array}$} & \multirow{3}{*}{$\begin{array}{c}\text { Mean net } \\
\text { displacement } \\
(\mathrm{cm} \pm \mathrm{SE}) \\
\left({ }^{\circ} \mathrm{M}\right)\end{array}$} & \multicolumn{3}{|c|}{ Mean scallop vector } & \multicolumn{4}{|c|}{ Main current vectors } \\
\hline & & & & & \multirow{2}{*}{$\begin{array}{c}\text { Dir }\left({ }^{\circ} \mathrm{M}\right) \\
( \pm 95 \% \mathrm{CI}) \\
\left(\mathrm{cm} \mathrm{s}^{-1}\right)\end{array}$} & \multirow{2}{*}{$\begin{array}{l}\text { Dist. } \\
(\mathrm{cm}) \\
\left({ }^{\circ} \mathrm{M}\right)\end{array}$} & \multirow{2}{*}{$\begin{array}{c}r \\
\left(\mathrm{~cm} \mathrm{~s}^{-1}\right)\end{array}$} & \multicolumn{2}{|c|}{ Primary } & \multicolumn{2}{|c|}{ Secondary } \\
\hline & & & & & & & & Dir. & Speed & Dir. & Speed \\
\hline 14. Sep & 0.2 & 1 & 16 & $138 \pm 22$ & 102 & 38 & $0.22^{\mathrm{ns}}$ & $305^{n s}$ & 10 & $120^{\text {ns }}$ & 6 \\
\hline 14 Sep & 0.2 & 2 & 17 & $159 \pm 36$ & $163 \pm 31$ & 108 & $0.58 *$ & $305^{\mathrm{ns}}$ & 10 & $120^{\circ}$ & 6 \\
\hline 15 Sep & 1 & 1 & 24 & $347 \pm 43$ & $124 \pm 28$ & 282 & $0.75^{\prime}$ & $305^{\text {ns }}$ & 15 & $120^{*}$ & 6 \\
\hline 15 Sep & 1 & 2 & 22 & $189 \pm 30$ & $164 \pm 23$ & 155 & $0.70^{\circ}$ & $305^{\text {ns }}$ & 15 & $120^{\circ}$ & 6 \\
\hline $16 \mathrm{Sep}$ & 2 & 1 & 29 & $452 \pm 51$ & $138 \pm 24$ & 337 & $0.60^{*} \cdot$ & $305^{\text {ns }}$ & 15 & $120^{\circ}$ & 6 \\
\hline $16 \mathrm{Sep}$ & 2 & 2 & 23 & $292 \pm 43$ & $165 \pm 35$ & 164 & $0.53^{\circ}$ & $305^{\text {ns }}$ & 15 & $120^{\circ}$ & 6 \\
\hline $17 \mathrm{Sep}$ & 3 & 1 & 29 & $478 \pm 57$ & $135 \pm 27$ & 317 & $0.48 *$ & $305^{\text {ns }}$ & 15 & $120^{*}$ & 6 \\
\hline $17 \mathrm{Sep}$ & 3 & 2 & 23 & $378 \pm 51$ & $156 \pm 46$ & 100 & $0.37^{\circ}$ & $305^{\mathrm{ns}}$ & 15 & $120^{\circ}$ & 6 \\
\hline $18 \mathrm{Sep}$ & 4 & 1 & 24 & $560 \pm 59$ & $143 \pm 28$ & 372 & $0.55 \cdots$ & $305^{\mathrm{ns}}$ & 15 & $120^{\cdots}$ & 6 \\
\hline $18 \mathrm{Sep}$ & 4 & 2 & 22 & $444 \pm 55$ & $126 \pm 28$ & 306 & $0.58 *$ & $305^{\text {ns }}$ & 15 & $120^{\circ}$ & 6 \\
\hline $21 \mathrm{Sep}$ & 7 & 1 & 25 & $762 \pm 107$ & $121 \pm 19$ & 571 & $0.68 \cdots$ & nd & nd & nd & nd \\
\hline $21 \mathrm{Sep}$ & 7 & 2 & 23 & $561 \pm 66$ & 147 & 81 & $0.25^{\mathrm{ns}}$ & nd & nd & nd & nd \\
\hline
\end{tabular}

Movement frequency tended to increase towards the end of the spring study as water temperature increased. For example, at the Bay Site in March,
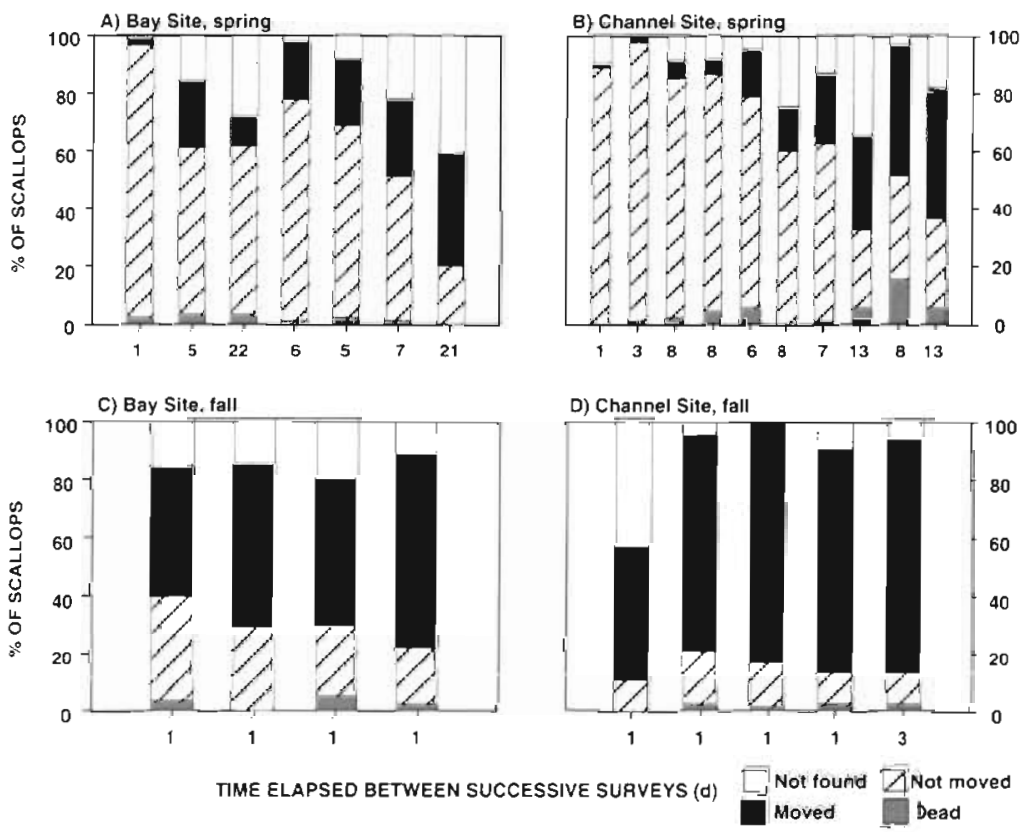

Fig. 5. Placopecten magellanicus. Percentage frequency histograms showing, between 2 consecutive surveys, the effect of (A-B, C-D) site and (A-C, B-D) season on the proportion of juvenile scallops found at their previous location on the sea bed ('not moved'), not found at their previous location on the sea bed but found within the search area ('moved'), not found at their previous location on the sea bed or within the search area ('not found') and mortality within the search area ('dead'). For each site and season, data from both stations were pooled. The second set of scallops released at Stn 1 in the spring at both study sites is included when the water temperature was $\sim 1^{\circ} \mathrm{C}$, the proportion of scallops not found at their previous location on the sea bed after $22 \mathrm{~d}$ (between 2 consecutive surveys) was significantly lower $(\mathrm{p}<$ 0.01 ) than that after a similar interval in May when the water temperature was $\sim 6^{\circ} \mathrm{C}$ (Fig. 5A). A similar trend was observed at the Channel Site (Fig. 5B). This positive relationship between scallop activity and water temperature is clear when movement frequency is compared for similar time intervals between the spring and fall studies. For example, in the spring study, $64 \%$ of scallops at the Bay Site and $54 \%$ of scallops at the Channel Site were not found at their release point after 29 and 27 d respectively (Fig. 4A, B). In the fall, movement frequency was much higher: $89 \%$ of scallops at the Bay Site and $98 \%$ of scallops at the Channel Site were not found at their release point after $2 \mathrm{~d}$ (Fig. 4C, D).

\section{Net displacement}

In the spring study, the distributions of net displacement of scallops at each site did not differ significantly between stations in any survey (KolmogorovSmirnov test: $p>0.11$, except for the 
A) Bay Site, 1 d

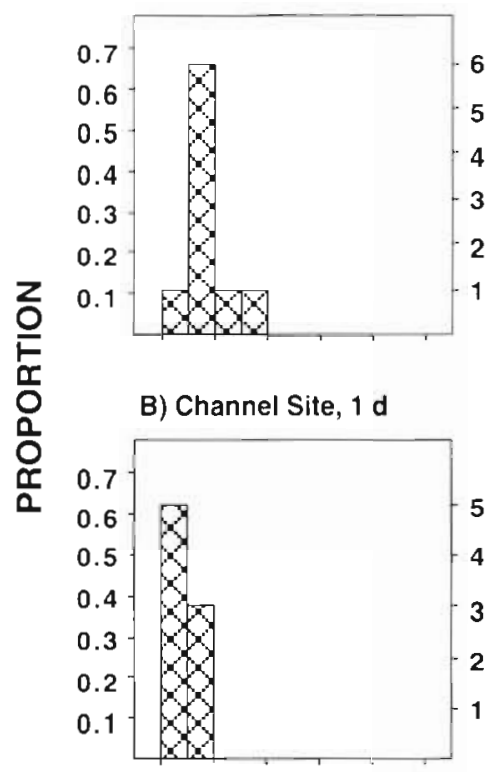

C) Bay Site, $29 d$

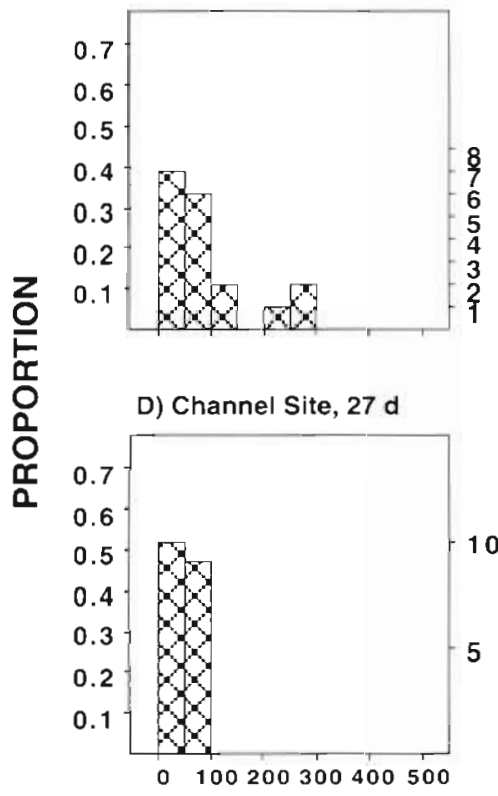

E) Bay Site, 2 d

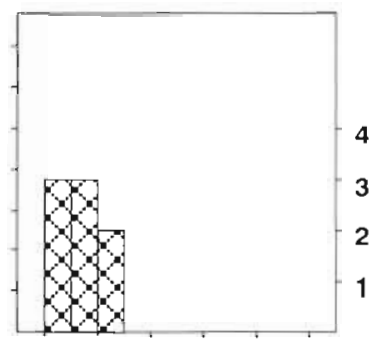

F) Channel Site, 2 d

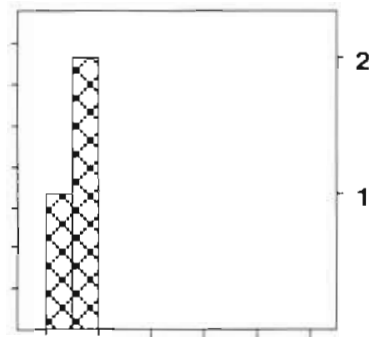

G) Bay Site, $35 \mathrm{~d}$

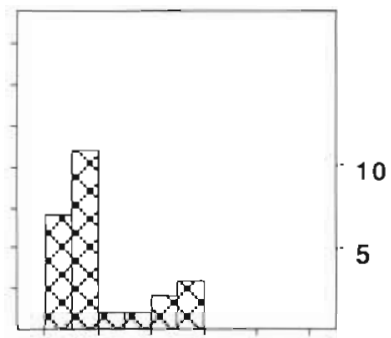

H) Channel Site, $35 d$

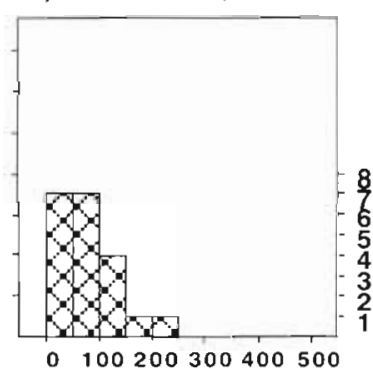

I) Bay Site, $7 \mathrm{~d}$

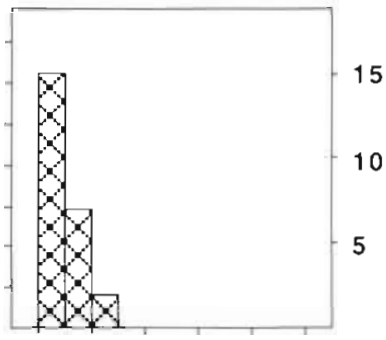

J) Channel Site, 5 d

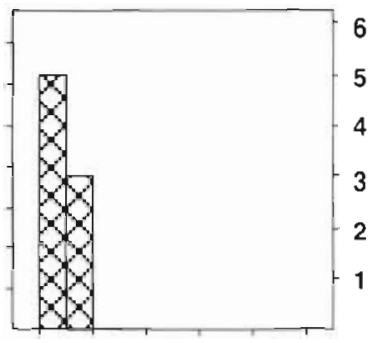

$\frac{\infty}{\frac{1}{2}}$

K) Bay Site, $40 \mathrm{~d}$

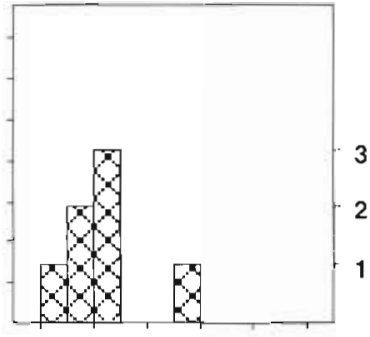

L) Channel Site, $42 d$

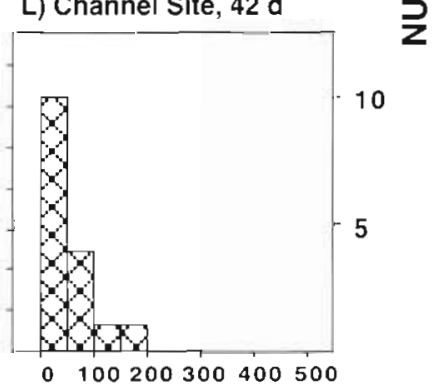

NET DISPLACEMENT (cm)

Fig. 6. Placopecten magellanicus. Spring study, frequency distributions of the net displacement ( $50 \mathrm{~cm}$ intervals) of juvenile scallops for 2 study sites, for which comparisons between sites could be made (A-B, C-D, E-F, G-H, I-J, K-L), measured as the net displacement from their release point on the sea bed to where they were found at each survey. For each site, data from both stations were pooled. The second set of scallops released at Stn 1 is not included

survey done $7 \mathrm{~d}$ after release at the Bay Site $(\mathrm{p}<0.05)$. (The second set of scallops released at Station 1 on April 4 at the Bay Site and on April 8 at the Channel Site were not included in this analysis.) Therefore, data from both stations were pooled for each site and for surveys up to $42 \mathrm{~d}$ after release (for which comparisons between sites could be made). The pooled distributions did not differ significantly between sites for any survey ( $p>0.51$; Fig. 6), except for those done 29 and 27 , and 40 and $42 \mathrm{~d}$ after release for the Bay Site and the Channel Site respectively $(p<$ $0.05)$. 


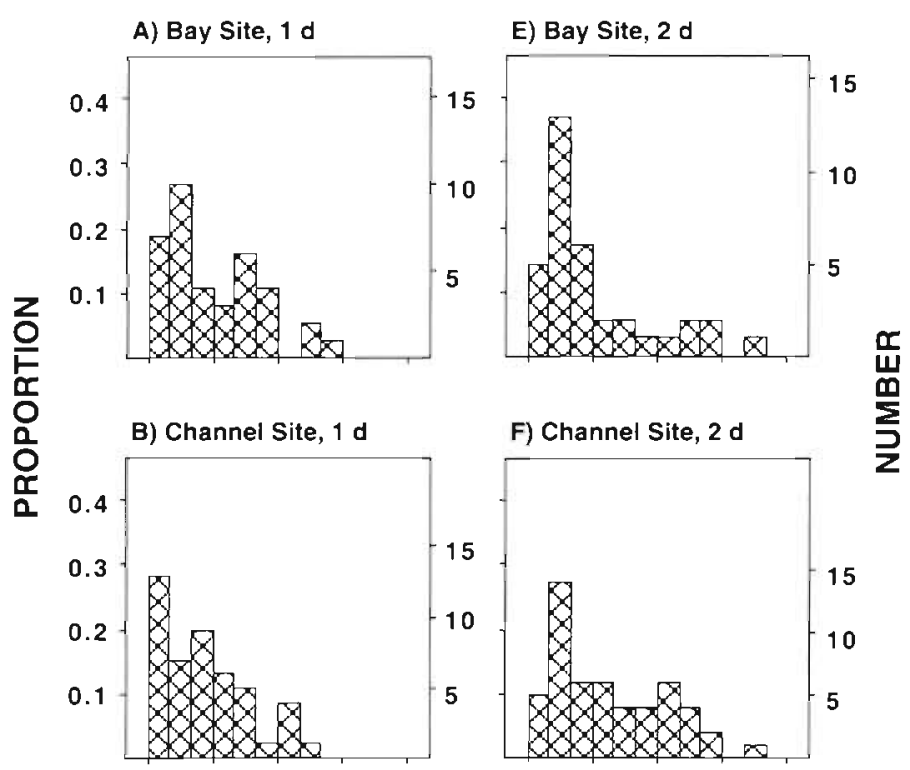

C) Bay Site, 3 d

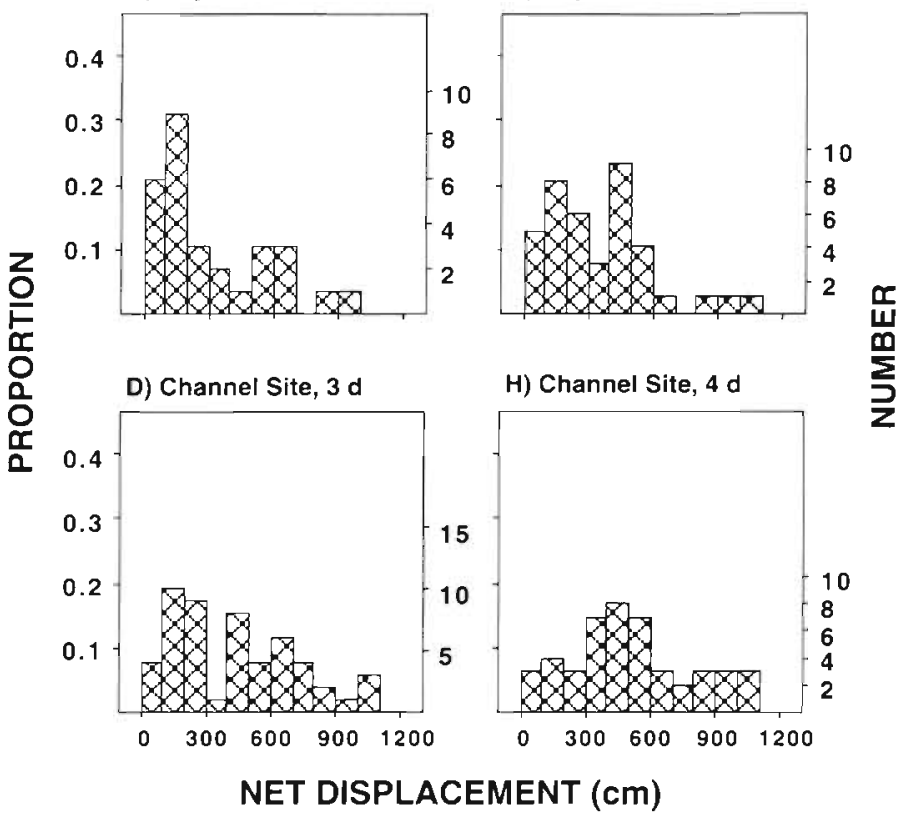

Fig. 7. Placopecten magellanicus. Fall study, frequency distributions of the net displacement $(100 \mathrm{~cm}$ intervals) of juvenile scallops for 2 study sites, for which compansons between sites could be made $(A-B, C-D, E-F, G-H)$, measured as the net displacement from their release point to where they were found at each survey. For each site, data from both stations were pooled

In the fall study, there was a significant difference in the distributions of net displacement between stations in only 2 surveys ( 3 and $4 \mathrm{~d}$ after release) at the Bay Site (Kolmogorov-Smirnov test: $p=0.03$ and $p=0.04$ respectively) and in only 1 survey ( $1 \mathrm{~d}$ after release) at the Channel Site $(p=0.02)$. Therefore, comparisons between sites were made after pooling the data from both stations for each site. The pooled distributions of net displacement did not differ significantly between sites, except for the survey $4 \mathrm{~d}(\mathrm{p}$ $=0.03$ ) after release (Fig. 7).

For surveys up to $7 \mathrm{~d}$ after release (for which comparisons between seasons could be made) the distribution of the net displacement of scallops differed significantly between the spring and fall studies (Kolmogorov-Smirnov test: $\mathrm{p}<$ 0.01, data from both sites pooled) (Figs. $6 \& 7$ ). Scallops moved about 3 times the distance during the first day after release in fall than in spring. The same tendency was observed for longer periods (Tables 1 to 4 ). The high movement frequency of scallops observed during the fall between 2 consecutive surveys ( $1 \mathrm{~d}$; Fig. 5C, D), was not translated into a large net displacement since $>60 \%$ of net displacements were $<3$ m (data from both stations pooled) (Fig. 8).

\section{Net movement direction}

In the spring study, there was no clear relationship between the net movement direction of scallops and the direction of the main current vectors at either site (Tables 1 \& 2, Fig. 9A, B). At the Bay Site, $39 \%(n=7)$ of the mean net movement directions of scallops differed significantly from randomness (Rayleigh's test: $p<0.05$, Table 1). In 2 surveys at Station 2 in which current meter data were available ( 7 and $29 \mathrm{~d}$ after release), scallop movement was significantly related to the direction of the primary current vector ( $V$ test: $\mathrm{p}<0.05$; Table 1 ). The directional movement observed for the second set of scallops released at Stn 1 at the Bay Site may be related to the direction of the primary current vector, since the confidence interval of the mean vector angles included the angle of the primary (ebb) tidal current (35 to $120^{\circ} \mathrm{M}$ ) (Hatcher unpubl, data). Mean net movement directions between stations at the Bay Site were not compared because significant directional movement at both stations was never observed simultaneously (i.e. in the same survey). At the Channel Site, $52 \%(\mathrm{n}=12)$ of the mean net movement directions of scallops differed significantly from randomness (Table 2). In 3 (13, 25 and $27 \mathrm{~d}$ after release) out of 6 surveys in which current meter data were available, the net movement direction of the scallops was significantly related to the direction of the primary current vector (Table 2). For the only survey (excluding the second set of scallops released at Stn 1) in which a significant directional movement was 
A) Bay Site, fall

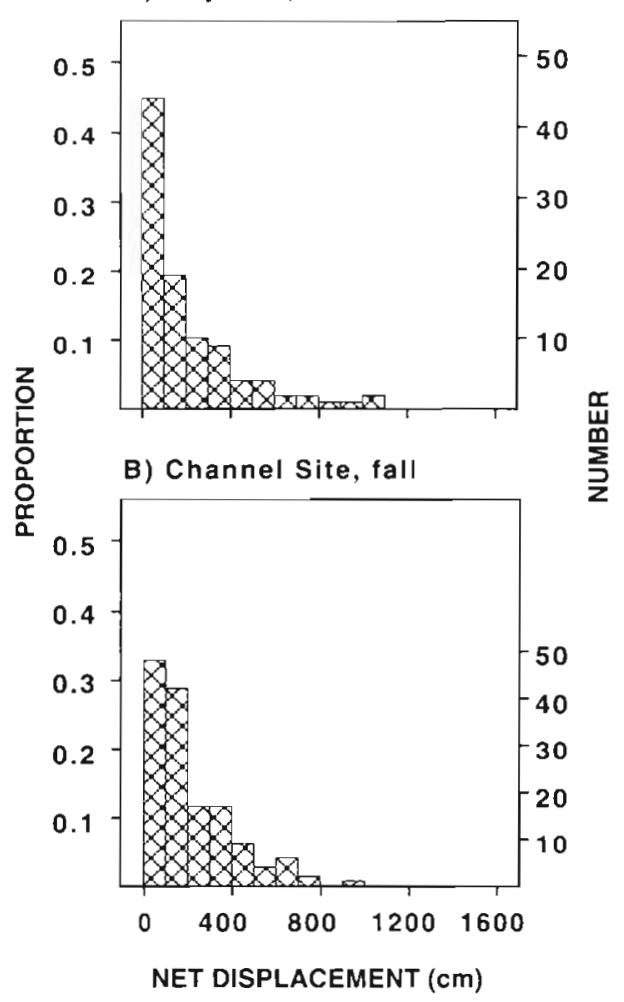

Fig. 8. Placopecten magellanicus. Fall study, frequency distributions of the net displacement $(100 \mathrm{~cm}$ intervals) of juvenile scallops for 2 study sites (A, B), measured as the net displacement between 2 consecutive surveys done after $1 \mathrm{~d}$. For each site, data from both stations and surveys done after $1 \mathrm{~d}$ were pooled detected (Rayleigh's test: $\mathrm{p}<0.05$ ) for both stations simultaneously (27 d after release; Table 2), the mean net movement direction differed significantly between stations (Watson and Williams test: $p<0.01$ ). At Station 2 there was a trend in successive surveys from a mean net movement angle of $120^{\circ}$ towards $200^{\circ} \mathrm{M}$. The lack of current meter data for the latter part of this study leaves open the possibility that this shift was related to a change in the direction of the main current vectors.

During the shorter fall study, the relationship between net movement direction of scallops and the direction of the main current vectors was clearer (Tables 3 \& 4, Fig. 9C, D). At the Bay Site, 90\% $(\mathrm{n}=9$ ) of the mean net movement directions of scallops differed significantly from randomness (Rayleigh and/or $V$ tests: $p<0.05$; Table 3). For both stations, the vector angles tended to be clustered around the direction of the primary current vector (Table 3). For 3 of the 4 surveys in which there was a significant directional movement for both stations simultaneously $(0.1,1$ and $2 \mathrm{~d}$ after release), the mean net movement direction did not differ significantly between stations (Watson and Williams test: $p>0.05$; Table 3); for the other survey ( $3 \mathrm{~d}$ after release) the stations differed significantly $(p<0.05)$. In the final survey (4 d after release) no significant directional movement was found at either station. At the Channel Site, $83 \%(\mathrm{n}=10)$ of the mean net movement
Fig. 9. Placopecten magellanicus. Net displacement and movement direction (with respect to magnetic north) of individual juvenile scallops at 2 study sites and seasons. For the spring study, net movement distance and direction of scallops correspond to those measured 7 and $5 \mathrm{~d}$ after scallops were released, at (A) the Bay Site and (B) the Channel Site respectively. For the fall study, net movement distance and direction of scallops correspond to those measured $4 \mathrm{~d}$ after scallops were released (C) at the Bay Site and (D) the Channel Site respectively. For the Bay and Channel sites, net displacement and direction of scallops correspond to those measured at Stns 2 and 1 respectively. Dashed lines: direction of main current vectors over the timeintegrated periods shown for each graph (- - - : primary; — - : secondary)
A) Bay Site, spring

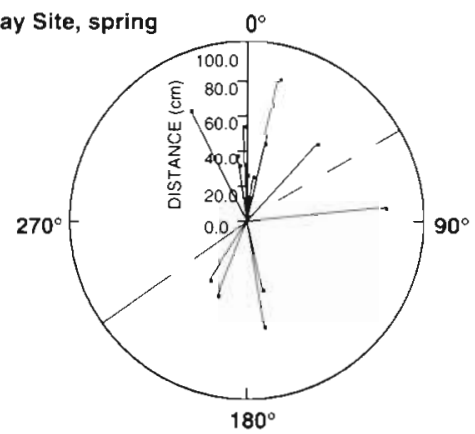

B) Channel Site, spring

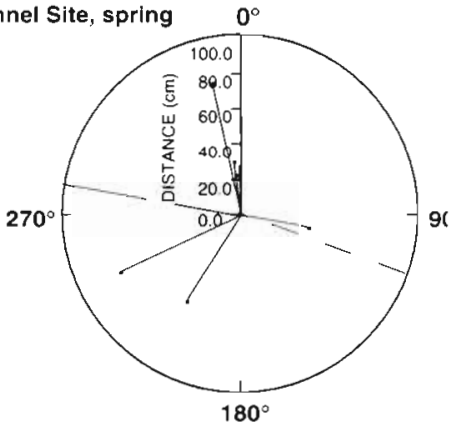

C) Bay Site, fall

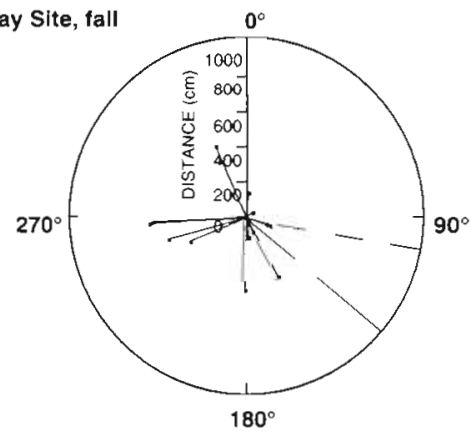

D) Channel Site, fall

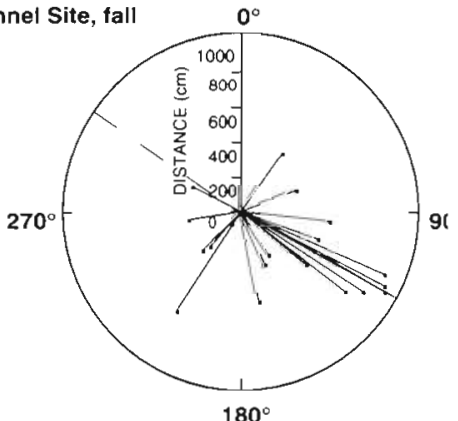


directions of scallops differed significantly from randomness (Rayleigh's test: $p<0.05$; Table 3 ). Differences in the mean net movement directions between stations were generally low $\left(\sim 30^{\circ}\right.$; Table 4$)$. For the 4 surveys in which there was a significant directional movement (Rayleigh's test: $p<0.05$ ) for both stations simultaneously $(1,2,3$ and 4 d after release), the mean net movement direction differed significantly between stations (Watson and Williams test: $p<0.05$ ) only for the survey $1 \mathrm{~d}$ after release (Table 4 ). For the final survey ( 7 d after release) there was no clear pattern in the net movement direction of scallops between stations and significant directional movement was observed at only 1 station (Table 4). In contrast to the results at the Bay Site, the movement vectors of scallops at the Channel Site were significantly related to the direction of the secondary current vector $(V$ test: $p<0.05)$.

\section{DISCUSSION}

In the interpretation of our results, we have made no distinction between scallops that have 'moved' (not found at their previous location on the sea bed but found within the search area) and those that were 'not found' (within the search area) in the calculation of the movement frequency (although the proportions of 'moved' and 'not found' scallops are given). This may result in some overestimation of the natural movement frequency of scallops, because some of the 'not found' scallops may have died rather than moved. This error was partially corrected by locating the tagged shells or shell fragments of dead scallops within the survey areas. Moreover, the proportion of scallops 'moved' and 'not found' at each survey followed a similar pattern in both the spring and fall studies. Also, since we only searched for scallops within a $10 \mathrm{~m}$ radius of the release point, we may be underestimating movement frequency and displacement by excluding scallops that moved outside of the search area. However, $75 \%$ of scallops found in a given survey were relocated in the next survey (see Fig. 5), in both the spring and fall studies. Therefore, we consider that pooling 'moved' and 'not found' scallops provides a reasonable estimation of movement frequency.

Our findings demonstrated a seasonal variation in the movement frequency of scallops, presumably related to temperature. At both sites, movement of scallops was significantly higher during the fall than during the spring. This is consistent with observations by Parsons \& Dadswell (1992) that swimming of Placopecten magellanicus in Passamaquoddy Bay has a seasonal pattern, with few scallops swimming during the winter when water temperature was minimal $\left(<4^{\circ} \mathrm{C}\right)$ and a peak of activity during the fall when temperature was maximal. During our fall study, when water temperature was $\sim 12^{\circ} \mathrm{C},-75 \%$ of scallops had at least 1 swimming excursion in a 1 to $4 \mathrm{~d}$ interval. This is higher than previous observations in Passamaquoddy Bay by Parsons et al. (1992), who found that $\sim 75 \%$ of juvenile $P$. magellanicus ( 15 to $25 \mathrm{~mm} \mathrm{SH}$ ) had at least 1 swimming excursion in 15 to $21 \mathrm{~d}$ intervals in the summer when water temperature was $\sim 10^{\circ} \mathrm{C}$.

Barbeau et al. (1994) documented differences between the Bay Site and the Channel Site in the activity and density of predatory crabs Cancer irroratus and starfish Asterias spp. The density of crabs was higher

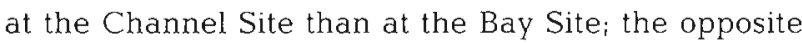
was found for starfish. For both sites, there was a positive correlation between predation rate and water temperature, although this was more evident for starfish than for crabs. Barbeau et al. (1994) also showed that scallops in the size range used in our study had a low probability of being captured by starfish, but a high probability of being captured by crabs. Differences in predator abundance and behaviour between the study sites, which may influence scallop swimming behaviour (mainly an escape response from predators), probably contribute to the significant interaction found between site and season on the movement frequency of scallops.

Differences in the observed distribution of net displacement of scallops between stations or sites for each season were not high enough to be considered biologically relevant. However, differences in movement frequency of the scallops between the spring and fall studies resulted in much higher net displacement in fall than in spring (e.g. 3 times higher during the first day after release).

The main current vectors and the net movement direction of juvenile Placopecten magellanicus were not strongly related, especially during the spring study. However, in those cases where the distribution of net movement direction of scallops was significantly different from random, it was often related to the direction of one of the 2 main current vectors. However, small sample sizes in many of the surveys in the spring study limited our ability to detect a significant mean net movement direction. At the Bay Site, in both the spring and fall studies, we observed a tendency towards a relationship between the net displacement direction and the primary current vector (main vector with highest speed). This is consistent with results found in short-term flume and field studies, in which flow speeds of about $20 \mathrm{~cm} \mathrm{~s}^{-1}$ determined the net movement direction of individual swimming trajectories of juvenile $P$. magellanicus (Carsen 1994). In contrast, at the Channel Site, the net movement direction of scallops was generally independent of the direction 
of the main current vectors in the spring study and it was related to the direction of the secondary current vector (mean vector with lowest speed) in the fall study.

In understanding the relationship between net movement direction of scallops and main current vectors, we are aware of the fact that the $\mathrm{S} 4$ current meter integrates current velocity over a $50 \mathrm{~cm}$ sphere and, therefore, possible variations in the local flow over the study area were assumed to be not significant. However, we consider this a fair assumption because we selected study sites with defined hydrodynamic regimes and, moreover, at each site during the spring study (when more than one current meter was available), current velocity records from both current meters (100 $\mathrm{m}$ apart along a line parallel to the major axis of current flow) were similar (Tables 1 \& 2).

Our results indicate that even in areas with welldefined current regimes, net movement direction of juvenile sea scallops is highly variable, especially over extended periods. Previous studies of adult Placopecten magellanicus ( $\sim 60 \mathrm{~mm} \mathrm{SH}$ ) using the markrecapture techniques indicated a weak positive relationship between the net movement direction of $P$. magellanicus and the current patterns on Georges Bank (Northwest Atlantic) (Posgay 1981, Melvin et al. 1985). Caddy (1968) observed that at bottom current speeds of $21 \mathrm{~cm} \mathrm{~s}^{-1}$ the direction of swimming of adult $P$. magellanicus is independent of current direction. Posgay (1981) suggests that the direction of swimming is probably random and that net movement over time is the result of tidal currents. This is consistent with observations by Thouzeau et al. (1991) that the age distribution of $P$. magellanicus on the eastern part of Georges Bank is spatially consistent with current-related dispersion. However, in seeding trials conducted concurrently with our spring study, we observed that the spatial patterns of dispersion of the seeded juvenile sea scallops showed a directionality which was not always explained by the prevailing current vectors (Hatcher unpubl. data). In another seeding trial near the Bay Site, Hatcher et al. (in press) observed that the dispersion pattern of 10000 seeded juvenile sea scallops was not significantly related to the near-bed tidal or residual current directions over 13 mo. Taking into account that juvenile $P$. magellanicus spend a relatively short time swimming in the water column $(-5 \mathrm{~s}$ of active swimming and $\sim 4$ of passive sinking; Carsen 1994), the timing of swimming relative to the current regime, rather than the time-averaged current, is likely to be the crucial factor determining the net movement direction of seeded juveniles. It has been suggested that Argopecten irradians and Chlamys islandica swim in response to tidal changes or flow speed
(Moore \& Marshall 1967, Gruffydd 1976). However, in other field experiments, we found that juvenile $P$. magellanicus did not swim in response to tidal changes (Carsen unpubl. data).

Our results, in conjunction with those of Hatcher et al. (in press), lead us to conclude that the local hydrodynamic regime alone is not a good predictor of the dispersion of juvenile sea scallops in natural habitats. Rather, we agree with Brand (1991) that the interaction between scallop behaviour (e.g. swimming frequency and intensity), and various physical (e.g. bottom type, water temperature, current direction and speed) and biological (e.g. predator type and abundance, scallop density) factors determines the patterns of scallop movement on a local scale.

Acknowledgements. We thank Dr J. Eckman for his advice on the design of the experiments, T. Balch and M. Barbeau for their diving assistance, and S. Kleinman who critically commented all versions of the manuscript. A.E.C. was supported by a Dalhousie Graduate Scholarship. The research was funded by a Natural Sciences and Engineering Research Council of Canada (NSERC) Networks of Centres of Excellence (Ocean Production Enhancement Network) Crant to R.E.S.

\section{LITERATURE CITED}

Barbeau MA, Scheibling RE (1994) Behavioural mechanisms of prey size selection by sea stars (Asterias vulgaris Verrill) and crabs (Cancer irroratus) preying on juvenile sea scallops (Placopecten magellanicus Gmelin). J exp mar Biol Ecol 180:103-136

Barbeau MA, Scheibling RE, Hatcher BG, Taylor LH, Hennigar AW (1994) Survival analysis of tethered juvenile sea scallops Placopecten magellanicus in field experiments: effects of predators, scallop size and density, site and season. Mar Ecol Prog Ser 115:243-256

Batschelet E (1981) Circular statistics in biology. Academic Press, London

Brand AR (1991) Scallop ecology: distributions and behaviour. In: Shumway SE (ed) Scallops: biology, ecology and aquaculture. Elsevier Science, Amsterdam, p 517-584

Caddy JF (1968) Underwater observations on scallop (Placopecten magellanicus) behaviour and drag efficiency. J Fish Res Bd Can 25:2123-2141

Carsen AE (1994) An analysis of the movement and swimming of the sea scallop (Placopecten magellanicus). MSc thesis, Dalhousie University, Halifax

Dadswell MJ, Weins D (1990) Size-related hydrodynamic characteristics of the giant scallop, Placopecten magellanicus (Bivalvia: Pectinidae). Can J Zool 68:778-785

Gruffydd LD (1976) Swimming in Chlamys islandica in relation to current speed and an investigation of hydrodynamic lift in this and other scallops. Norw $\mathrm{J}$ Zool 24 : $365-378$

Hatcher BG, Scheibling RE, Barbeau MA, Hennigar AW, Taylor LH (1993) 'Why not just throw them on the bottom?' Sea bed seeding of scallops in Nova Scotia. In: Pirguet KT (ed) Proceedings of the 10th Annual Meeting of the Aquaculture Association of Canada. Aquacult Ass Can Bull 93-4:132-134 
Hatcher BG, Scheibling RE, Barbeau MA, Taylor LH, Hennigar AW, Windust A (in press) Dispersion and mortality of a population of sea scallops (Placopecten magellanicus) seeded in a tidal channel. Can J Fish Aquat Sci

Joll LM (1989) Swimming behaviour of the saucer scallop Amusium balloti (Mollusca: Pectinidae). Mar Biol 102 299-305

Kleinman S, Hatcher BG, Scheibling RE, Taylor LH, Hennigar AW (in press) Shell and tissue growth of juvenile sea scallops, Placopecten magellanicus, in suspended and bottom culture in Lunenburg Bay, Nova Scotia. Aquaculture

Manuel JL, Dadswell MJ (1991) Swimming behaviour of juvenile giant scallop, Placopecten magellanicus, in relation to size and temperature. Can J Zool 69:2250-2254

Manuel JL, Dadswell MJ (1993) Swimming of juvenile sea scallops Placopecten magellanicus (Gmelin): a minimum size for effective swimming? J exp mar Biol Ecol 174:137-175

Melvin GD, Dadswell MJ, Chandler RA (1985) Movement of scallops Placopecten magellanicus (Gmelin 1791) (Mollusca: Pectinidae) on Georges Bank. CAFSAC Res Doc 85/30:1-29

Minchin D (1992) Biological observations on young scallops Pecten maximus. J mar biol Ass UK 72:807-819

Moore JK, Marshall N (1967) An analysis of the movements of the bay scallop, Aequipecten irradians, in shallow estuary. Proc natl Shellfish Ass 57:77-82

Naidu KS, Fournier R, Marsot P, Worms J (1989) Culture of the sea scallop Placopecten magellanicus: opportunities and constraints. In: Boghen AD (ed) Cold-water aquacul-

This article was presented by R. N. Hughes (Senior Editorial Advisor), Bangor, UK ture in Atlantic Canada. The Canadian Institute for Research on Regional Development, Moncton University, Moncton, NB, p 211-239

Parsons GJ, Dadswell MJ (1992) Seasonal and size-related swimming behaviour in the giant scallop, Placopecten magellanicus. In: Proceedings of Aquaculture '92, Growing toward the 21st century, Orlando, FL, USA, p 182

Parsons GJ, Warren-Perry CR, Dadswell MJ (1992) Movements of juvenile sea scallops Placopecten magellanicus (Gmelin 1791) in Passamaquoddy Bay, New Brunswick. J Shellfish Res 11:295-297

Posgay JA (1957) The range of the sea scallop. Nautilus 71(2): 55-57

Posgay JA (1981) Movement of tagged sea scallops on Georges Bank. Mar Fish Rev 43:19-25

Sturley DM, Leal R (1991) Hydrodynamic data. South Cove. Lunenburg Bay. In: OPEN Report, Dept of Oceanography, Dalhousie University, Halifax 1:1-36

Sturley DM, Thompson KR, Bowen AJ (1993) Fine-scale models of coastal inlets: a physical basic for water quality/biological models. In: Proceedings of the 1993 Canadian Coastal Conference, Vancouver, British Columbia, Canada, p 387-404

Thouzeau G, Ginelte R, Smith SJ (1991) Spatial variability in distribution and growth of juvenile and adult sea scallops Placopecten magellanicus (Gmelin) on eastern Georges Bank (Northwest Atlantic). Mar Ecol Prog Ser 74:205-218

Wildish DJ, Kristmanson DD (1988) Growth responses of giant scallops to periodicity of flow. Mar Ecol Prog Ser 42: $163-169$

Manuscript first received: January 13, 1995

Revised version accepted: April 15, 1995 